\title{
A Hybrid MCDM Method Using Combination Weight for the Selection of Facility Layout in the Manufacturing System: A Case Study
}

\author{
Shanshan Zha $\mathbb{D}^{D}$, Yu Guo, Shaohua Huang $\mathbb{D}^{D}$, and Shengbo Wang \\ College of Mechanical and Electrical Engineering, Nanjing University of Aeronautics and Astronautics, Nanjing, 210016, China \\ Correspondence should be addressed to Shanshan Zha; sszha@nuaa.edu.cn
}

Received 23 July 2019; Revised 15 December 2019; Accepted 3 January 2020; Published 7 February 2020

Academic Editor: Elena Zaitseva

Copyright ( 2020 Shanshan Zha et al. This is an open access article distributed under the Creative Commons Attribution License, which permits unrestricted use, distribution, and reproduction in any medium, provided the original work is properly cited.

\begin{abstract}
Facility layout in the manufacturing system is an elaborate production activity since multiple, uncertain, and conflicting factors would affect facility layout decisions. Selecting the best facility layout among alternatives is considered as a problematic multicriteria decision-making (MCDM) problem. Generally, the facility layout is evaluated by the MCDM method with redundant factors, separate weights, and independent relationships between factors. To overcome this defect, this paper intends to propose a hybrid fuzzy MCDM method with combination weight (CW) based on integration with Delphi, fuzzy ANP, Entropy, and fuzzy PROMETHEE (CW-DFAE-FP) to select the most suitable facility layout alternative in an aircraft assembly workshop. The application results indicate that this method can effectively obtain the most suitable alternative for facility layout selection. Furthermore, the comparative analysis with other MCDM methods verifies the effectiveness of the proposed method and reveals the selection of weight has an impact on final priority ranking. Finally, sensitivity analysis highlights the performance of the proposed method and provides strategic insights to identify the critical criteria for the best alternative in facility layout.
\end{abstract}

\section{Introduction}

Facility layout plays a crucial role in the modern manufacturing system. Facility layout problem (FLP) involves the suitable arrangement of facilities (i.e., workstations, machines, and material handling equipment) in such a way to obtain maximum production efficiency and profits [1]. Higher production costs, more work-in-process inventory, poorer flexibility, longer lead-time, etc. are a possible consequence of improper facility layout. A rational facility layout can significantly improve the overall productivity and production efficiency and reduce production cycles [2].

Due to multiple, uncertain, and conflicting criteria, the facility layout selection is a time consuming and problematic MCDM problem. The multicriteria decision-making (MCDM) method can capture all of the quantitative and qualitative criteria simultaneously $[3,4]$. It is always employed in handling MCDM problem that selects a suitable solution among alternatives concerning a variety of factors.
Fuzzy numbers can qualify the vagueness in decision makers' (DMs') expression and improve the precision of the MCDM method [5]. Therefore, various fuzzy MCDM methods have been presented in the literature, for example, fuzzy analytic network process (FANP) [6], fuzzy data envelopment analysis (FDEA) [7], intuitionistic FANP (IFANP) [8], intuitionistic fuzzy preference ranking organization methods for enrichment evaluation (IF-PROMETHEE) [9], multihesitant fuzzy elimination and choice translating reality (ELECTRE) [10], and double normalization-based multiple aggregation (DNMA) method [11].

Over the last few decades, many fuzzy MCDM methods or combination of other fuzzy MCDM methods are used in the literature to tackle facility layout selection (FLS). Çebi and Otay [12] used fuzzy technique for order preference by similarity to an ideal solution (TOPSIS) to solve the FLS. Altuntas et al. [13] applied a fuzzy decision-making trial and evaluation laboratory- (DEMATEL-) based approach for FLS. Shokri et al. [14] proposed the AHP-Višekriterijumska Optimizacija i kompromisno Rešenje (VIKOR) method for 
facility layout design. Özdağoğlu [15] used a FANP approach to prioritize the alternatives for facility location selection. Ertuğrul and Karakaşoğlu [16] compared fuzzy AHP and fuzzy TOPSIS for facility location selection. Wang et al. proposed an FANP and TOPSIS method to select an energy plant location [6].

The literature review shows that different varieties of MCDM methods, such as FAHP, DEAMATEL, VIKOR, FTOPSIS, FANP, have been applied to FLS. Nevertheless, these methods use the same scale and preference function for evaluation alternatives [17]. The preference functions in line with contradictory or different criteria that have a serious effect on the accuracy of decision-making results $[17,18]$. Due to simple implementation and tackling incomparability [9], FPROMETHEE is appreciably suitable to rank alternatives. Similar to other traditional MCDMs, a disadvantage of PROMETHEE is the need for determination of criteria weight before implementation [19]. Therefore, PROMETHEE is always integrated with other MCDM methods to the solve MCDM problem. Avikal et al. [20] proposed FAHP and PROMETHEE methods for disassembly line balancing problems. Brankovic et al. [21] proposed the entropyPROMETHEE II method for evaluation of hydraulic structures alternatives. Mousavi et al. [22] proposed an integrated Delphi-AHP-PROMETHEE method for plant location selection. Mohamed et al. [23] proposed modified DelphiFAHP-PROMETHEE for geospatial business intelligence selection. Among these AHP-based and entropy-based methods, the premise is that all evaluation criteria and factors are independent $[3,24]$. Its inaccuracy in the practical application may lead to poor decision making. Moreover, various existing PROMETHEE methods or combination with other methods are applied based on single subjective or objective weight (i.e., FAHP, FANP, Entropy, etc.). Few researchers consider PROMETHEE with DM'S preference and a weighted sum of both weights simultaneously.

To deal with the FLS problem, a hybrid fuzzy MCDM method with combination weight based on the integration of Delphi, FANP, Entropy, and FPROMETHEE II is proposed. To our knowledge, no previous studies have combined these four methods to tackle FLS. The purpose of integration is to propose a new fuzzy MCDM method that takes advantage merits of the above-mentioned methods for solving complex MCDM problems. For that reason, the Delphi method is employed to filter insignificant criteria and determine critical criteria by DMs to reduce the complexity and redundancy of the MCDM model. An integrated combination of FANP and Entropy is used to determine combination weights of each factor, which helps DMs overcome the subjective bias and reflect the essential characteristics of criterion. Furthermore, the FANP also has advantage of solving the complicated MCDM problem with its interrelationships among criteria. Lastly, the PROMETHEE is integrated with fuzzy set and combination weights to rank alternatives and select an optimal solution for facility layout in the manufacturing system.

The proposed hybrid method can solve multiple criteria with interdependency in the fuzzy environment and efficiently select the most suitable alternative in a complicated system. The proposed hybrid method applied for the facility layout selection in the manufacturing system fills the research gap. Additionally, this paper reinforces decisionmaking research by identifying a more preferred MCDM method on facility layout selection, which makes the selection process more rational and logical. Lastly, this paper provides strategic insights to identify the critical criteria for the best alternative in facility layout and presents the priority factors for future improvement.

The paper is presented as follows: Section 2 presents the problems description of facility layout in the manufacturing system. The proposed evaluation framework and methodology are presented in Section 3. The case of the facility layout in the aircraft assembly workshop is applied to verify the proposed methods in Section 4. Furthermore, the discussion of comparative analysis and sensitivity analysis is given in Section 5. Lastly, Section 6 presents the conclusion.

\section{Problems Description of Facility Layout in the Manufacturing System}

Generally, in the modern manufacturing system, material handling, flexibility, productivity, safety, and resource utilization are the main factors that have a significant impact on facility layout planning and implementation. The detailed explanations are described as follows:

(a) Material handling: the material transportation runs through the entire process from raw material to product in the large manufacturing workshop. For example, to save material handling costs, facilities with closely materials transportation need to be placed in adjacent locations.

(b) Flexibility: rapid response to market changes and various customer requirements is necessary for enhancing competitiveness in a modern manufacturing environment. It involves machine setup or removing, expansion in the production line and planning multiple transportation paths, etc., which affected the arrangement of facilities.

(c) Productivity: the execution of process and assembly tasks and operation machines affect the facility layout [25]. The location of facilities is affected by employee using the temporary facilities, such as auxiliary truss, tool cabinet, accessory equipment and working ladder, etc.

(d) Safety: there are many machines with high speed, high load, high impact and noise in manufacturing industries. To prevent and reduce accidents from working environments, safety is an essential objective in facility layout planning.

(e) Resources utilization: the resources in manufacturing systems such as employee, equipment, and space etc. are also have an impact on facility layout. For example, some large facilities (i.e., hydraulic station, spray-painting workstation, and site office) are difficult to shift, which determines the necessary workspace and has an impact on the arrangement of facilities. 
Because of multiple attributes involved in facility layout of manufacturing system, it is a throne issue for decisionmakers to identify the factors that have an impact on facility layout. Therefore, it is necessary to systematically analyze the impact of various factors on the layout and select the best facility layout alternative by using MCDM methods.

\section{Proposed Facility Layout Evaluation Framework and Methodology}

This section proposes a multiphase evaluation framework for facility layout selection in the manufacturing system. The detail steps included in the evaluation framework are demonstrated in the following.

3.1. Proposed Evaluation Framework. The general view of proposed evaluation framework for facility layout selection in manufacturing system is shown in Figure 1. The proposed evaluation framework includes four main stages. The first phase aims to screen the critical criteria and factors by using Delphi. The main objective of the second phase is to obtain the subjective weight between factors by using FANP. The third phase measures the objective weight between factors by using Entropy. Lastly, rank all of candidate alternatives using the extended PROMETHEE method in the fourth stage.

\subsection{Methods for Evaluation Framework}

3.2.1. Screen the Critical Criteria and Factors with the Delphi Method. The Delphi method is firstly developed by researchers at the Rand Corporation [26]. It can be used to identify, synthesize, and analyze critical factors in the process of decision-making [27]. The Delphi method starts with an iteration process of the questionnaire from anonymous experts until a mutual consensus is achieved on the focused topic. It usually implements in the form of a questionnaire through various communication techniques (i.e., email, online, postal) to collect ideas, analyze terms, and reach a consensus from experts [28]. Delphi has been widely used to scrutinize the criteria in various applications such as information system management [29], cold chain improvement [30], foresight support system [31], etc. In this paper, we aim to use the Delphi method to screen the critical criteria and factors in facility layout. Based on the Delphi, the procedure of screen steps are as follows:

Step 1: collect expert group's opinions. A total of 18 experts from academia and industry had taken part in the survey for screening the evaluation factors by using email to respond to the questionnaire anonymously. The items in the questionnaire come from the available literature, experts' opinions, and practical investigation.

Step 2: calculate the coefficient of variation (CV) [32]. $\mathrm{CV}$ denotes standard deviation divided by the mean [27]. Analyze and modify the results of the first round survey by $\mathrm{CV}$ and start the second round questionnaire [33]. When the value of CV is less than or equal to 0.5 , the next round of surveys is terminated.

Step 3: calculate content validity ratio (CVR) [34]. CVR is used to measure how important a criterion or factor is. For retaining or removing a factor, the CVR with a threshold redefined is described as following:

$$
\mathrm{CVR}=\frac{N_{c r}-N / 2}{N / 2},
$$

where $N_{\text {cr }}$ denotes the number of critical factors and $N$ is the number of participating experts.

Step 4: screen critical factors. Factors can be filtered from numerous factors by setting a threshold of CVR. The range of CVR values is -1 to 1 . The measurement of CVR value is usually set at 0.29 [27]. If CVR value exceeds 0.29 , the criterion or factor is retained otherwise removed.

3.2.2. Obtain the Subjective Weight with an FANP Method. The ANP firstly developed by Satty [35], evaluates all relationships between criteria and factors by analyzing potential interdependence in the decision-making problems $[8,36]$. ANP is a useful decision-making technique that captures the outcome of dependency between criteria. However, imprecise and subjective judgments of DMs obstruct the application of the ANP [37]. Under this condition, the fuzzy set theory is combined with the ANP method. Based on the FANP, the procedure for obtaining the subjective weight is as follows:

Step 1: determine fuzzy scales corresponding to the linguistic term for evaluation. The relationship between factors is determined by pairwise comparison of one factor to another. To measure this relationship, the linguistic scale with corresponding triangular fuzzy number (TFN) is determined as Table 1 shows.

Step 2: pairwise comparisons are established among factors. The relative strength of each pair of factors forms comparison matrix, and the preference of experts' threshold in the comparison matrix is represented by using TFN again. The pairwise comparison matrix $\widetilde{P}^{\prime}$ is described as

$$
\widetilde{p}^{\prime}=\left[\begin{array}{cccc}
\widetilde{p}_{11}^{\prime} & \widetilde{p}_{12}^{\prime} & \cdots & \widetilde{p}_{1 n}^{\prime} \\
\widetilde{p}_{21}^{\prime} & \widetilde{p}_{22}^{\prime} & \cdots & \widetilde{p}_{2 n}^{\prime} \\
\vdots & \vdots & \vdots & \vdots \\
\widetilde{p}_{n 1}^{\prime} & \widetilde{p}_{n 2}^{\prime} & \cdots & \widetilde{p}_{n m}^{\prime}
\end{array}\right]
$$

where $\widetilde{p}_{i j}^{\prime}=\left(l_{i j}, m_{i j}, u_{i j}\right)$ denotes the importance of factor $i$ over the factor $j$, and $i=j=1,2, \ldots, n$.

Step 3: obtain the priority vectors. To form the multiple submatrices of the supermatrix, the priority vectors of each comparison matrix need to be obtained. The estimation of fuzzy priorities $\widetilde{w}_{k}$ can be acquired based on 


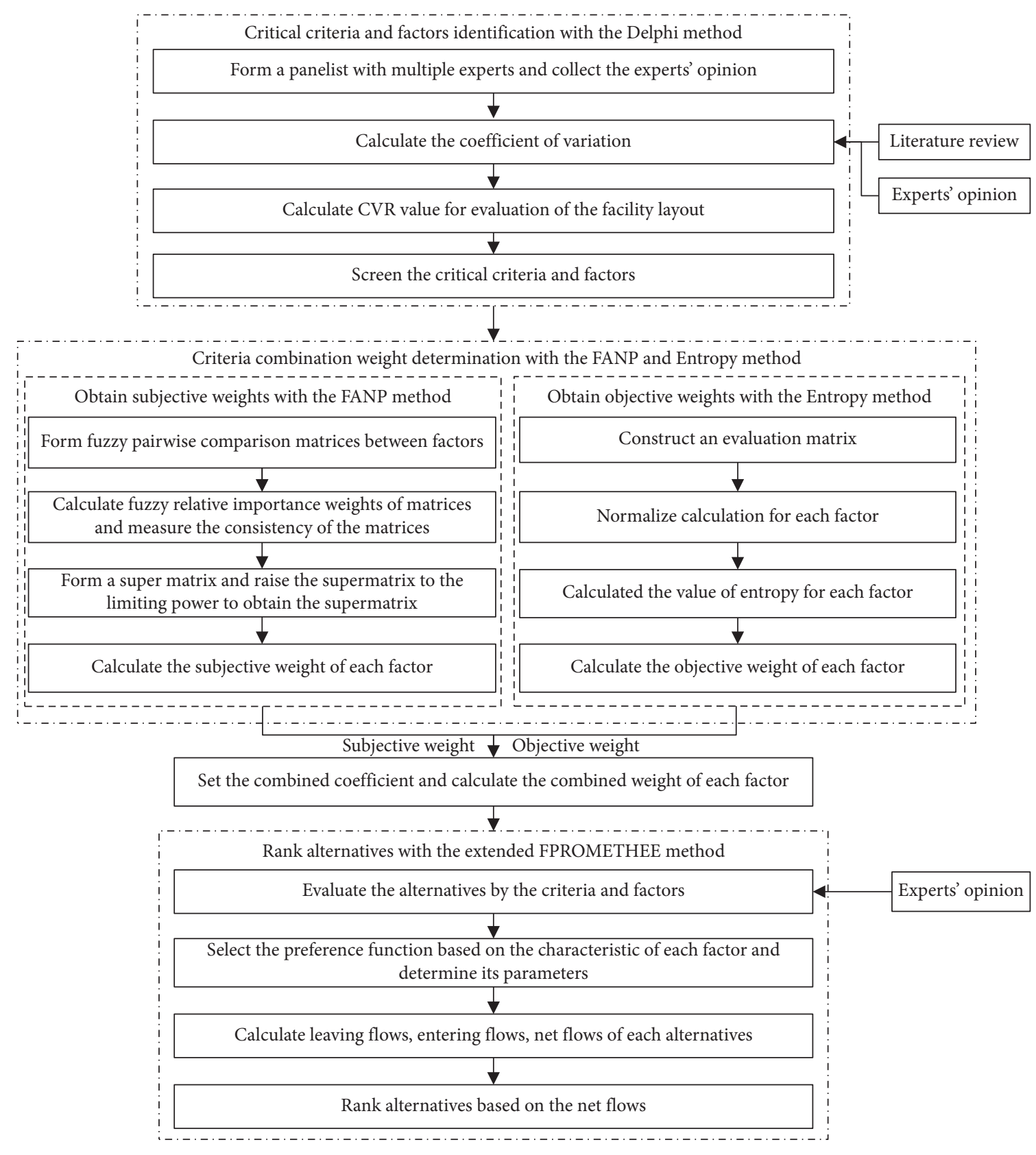

Figure 1: Proposed evaluation methodology framework.

TABle 1: The fuzzy scales (TFN) [36].

\begin{tabular}{lc}
\hline Linguistic terminology & Fuzzy scales \\
\hline None & $(0,0,0.1)$ \\
Very low & $(0,0.1,0.2)$ \\
Low & $(0.1,0.2,0.3)$ \\
Fairly low & $(0.2,0.3,0.4)$ \\
More or less low & $(0.3,0.4,0.5)$ \\
Medium & $(0.4,0.5,0.6)$ \\
More or less good & $(0.5,0.6,0.7)$ \\
Fairly good & $(0.6,0.7,0.8)$ \\
Good & $(0.7,0.8,0.9)$ \\
Very good & $(0.8,0.9,1)$ \\
Excellent & $(0.9,1,1)$ \\
\hline
\end{tabular}

the comparison matrix by multiple methods. The logarithmic least-square method is employed to calculate the weights in this study $[38,39]$. This method can convert fuzzy priorities into the crisp weights with normalization and defuzzification through

$$
\begin{gathered}
\widetilde{w}_{k}=\left(w_{k}^{l}, w_{k}^{m}, w_{k}^{u}\right), \quad k=1,2, \ldots, n, \\
P\left(a_{i j}\right)=\frac{l_{i j}+4 m_{i j}+u_{i j}}{6},
\end{gathered}
$$

where $w_{k}^{s}=\left(\prod_{i=1}^{n} p_{i j}^{s}\right)^{1 / n} / \sum_{i=1}^{n}\left(\prod_{i=1}^{n} p_{i j}^{s}\right)^{1 / n}, s \in\{l, m, u\}$. 
Step 4: calculate the consistency property for each matrix. The consistency property of the matrix has an impact on the quality of the results of ANP. The consistency index (CI) and consistency ratio (CR) [40] are calculated as follows:

$$
\begin{aligned}
\mathrm{CI} & =\frac{\lambda_{\max }-n}{n-1}, \\
\mathrm{CR} & =\frac{\mathrm{CI}}{\mathrm{RI}}
\end{aligned}
$$

where $\lambda_{\max }$ represents the largest eigenvalue of the matrix and RI denotes the random index. CR should be less than 0.1 and the comparisons are acceptable.

Step 5: set up a supermatrix. The supermatrix is composed of many submatrices, and each submatrix consists of a set of relationships between two factors. By placing the priority vectors into the suitable column, supermatrix can be established.

Step 6: calculate the limit supermatrix. To get a steadystate result, the supermatrix is raised to limiting power $2 p+1$ until it reaches stability, where $p$ is a sufficiently large number. The subjective weights of the criteria can be attained in the result and will be used in fuzzy PROMETHEE later.

\subsubsection{Obtain the Objective Weight with the Entropy Method.} Entropy was firstly introduced to information theory, which is used to measure signal uncertainty in information sources based on probability theory. The Entropy method is suited to assign the objective weight with its inherent information provided by data, and it has been verified by many researchers for obtaining the weight of criteria [41-43]. Based on the Entropy method, the procedure for obtaining the objective weight is as follows:

Step 1: calculate the value of entropy $E_{j}$ for each factor:

$$
E_{j}=-\frac{1}{\ln n} \sum_{i=1}^{n} f_{i j} \cdot \ln f_{i j}, \quad(i=j=1,2, \ldots ., n),
$$

where $f_{i j}$ denotes the normalized value of the factor $j$ for alternative $i$ by using

$$
f_{i j}=\frac{x_{i j}}{\sum_{i=1}^{m} x_{i j}}
$$

where $x_{i j}$ denotes the sample data for factor $j$.

Step 2: calculate the resource weights of each factor as follows:

$$
w_{j}^{o}=\frac{1-E_{j}}{n-\sum_{j=1}^{n} E_{j}}, \quad j=1,2, \ldots, n,
$$

where $w_{j}^{o}$ denotes the objective weight of each factor $j$.
3.2.4. Rank Alternatives with the Extended PROMETHEE II Method. The PROMETHEE method is one of the comprehensive and effective outranking methods [44]. By 2010, The PROMETHEE method had been extended to six versions, and the one used in this paper is PROMETHEE II. Compared with other versions of PROMETHEE, PROMETHEE II has the advantage of obtaining a complete ranking of alternatives. Additionally, PROMETHEE II allows for conflicting criteria with different units and dimensions [45]. This method has various applications in many fields, such as manufacturing and assembly [46], stock trading [47], air traffic controller's workloads stress [18], selection of travel plans [48], etc. Based on the PROMETHEE II method, the procedure for ranking alternatives are as follows:

Step 1: calculate for the deviation function. Let $A=$ $\left(a_{1}, a_{2}, \ldots, a_{k}\right)$ be a cluster of alternatives and $F=\left(f_{1}, f_{2}, \cdots f_{m}\right)$ be a cluster of factors. Comparative analysis between two alternatives $a_{i}$ and $a_{j}$ concerning the factor $k$ is conducted, and the deviation $\widetilde{d}_{k}$ of an alternative $a_{i}$ over the alternative $a_{j}$ is determined as

$$
\tilde{d}_{k}=\tilde{f}_{k}\left(a_{i}\right)-\tilde{f}_{k}\left(a_{j}\right)
$$

where $\tilde{f}_{k}\left(a_{i}\right)$ is the evaluation of the alternative $a_{i}$ corresponding to the factor $f_{k}$.

Step 2: select a suitable preference function for each factor. Six types of preference functions of the PROMETHEE method are presented as follows: (a) Usual criterion, (b) U-shaped criterion, (c) V-shaped criterion, (d) Level criterion, (e) V-shaped linear criterion, and (f) Gaussian criterion [49]. Each preference function has its corresponding meaning and applicable conditions [18]. The explanation is demonstrated as follows: usual criterion is always for qualitative criteria without determining any threshold value when DMs do not need to assign importance for the differences between criteria value. U-shaped criterion mainly applied for qualitative criteria with determining a single indifference threshold. V-shaped criterion is used in quantitative criterion with linear increase from 0 to 1 . Level criterion is applied for qualitative criteria with level change. Preference is considered to be average. $\mathrm{V}$-shaped linear criterion is mainly applied for quantitative criterion involving indifference and linear increased preference simultaneously. Lastly, Gaussian criterion is seldom used for its complexity when the preference of decision-makers increases with the deviation. For each criterion, only a few thresholds are determined interactively between the experts and DMs. It is essential to select the appropriate preference function of each factor according to its characteristics.

Step 3: evaluate all the alternatives $a_{i}, a_{j} \in A$. The fuzzy preference function incorporates the combinational weights to determine the preference function relation $\pi$ as in 


$$
\tilde{\pi}\left(a_{i}, a_{j}\right)=\sum_{j=1}^{m} p_{k}\left(d_{k}\right) w_{k}^{c}=\sum_{j=1}^{m} p_{k}\left(\widetilde{f}_{k}\left(a_{i}\right)-\tilde{f}_{k}\left(a_{j}\right)\right) w_{k}^{c},
$$

where

$$
w_{k}^{c}=\alpha w_{k}^{s}+(1-\alpha) w_{k}^{o}, \quad \alpha \in[0,1],
$$

where $w_{k}^{c}$ is the combinational weight of the factor $k$ acquired from the FA and Entropy methods, $p_{k}$ is the preference function for the factor $k$.

Step 4: calculate net flow (NF) of each alternative. The $\mathrm{NF}$ is employed to evaluate the performance of each alternative. The fuzzy positive flow is

$$
\tilde{\phi}^{+}\left(a_{i}\right)=\frac{1}{n-1} \sum_{i^{\prime}=1}^{n} \tilde{\pi}\left(a_{i}, a_{j}\right), \quad i \neq j .
$$

The fuzzy negative flow is

$$
\widetilde{\phi}^{-}\left(a_{i}\right)=\frac{1}{n-1} \sum_{i^{\prime}=1}^{n} \tilde{\pi}\left(a_{j}, a_{i}\right), \quad i \neq j,
$$

where $\tilde{\phi}^{+}\left(a_{i}\right)$ weighs the weakness of alternative $a_{i}$ while $\widetilde{\phi}^{-}\left(a_{i}\right)$ weighs the strength of alternative $a_{i}$.

Step 5: calculate the NF of each alternative. The NF $\phi\left(a_{i}\right)$ is expressed in

$$
\phi\left(a_{i}\right)=\widetilde{\phi}^{+}\left(a_{i}\right)-\widetilde{\phi}^{-}\left(a_{i}\right) .
$$

Step 6: rank alternatives based on NFs. The higher NF is ranking flow, the better the performance of the alternative.

\section{Case Study}

To validate the effectiveness of the proposed MCDM method, an expanding case study is presented in this section. A facility layout for an aircraft assembly workshop is selected to implement the proposed approach. In this case, the fixedstation layout design is used to improve product efficiency and save costs, in which facilities are assigned in the station or around the station because of large products and largescale components. For purposes of saving material handling costs, parts and equipment that have the same function in the assembly process are assigned in the same storage area around the station. In a typical large parts docking and assembly station, there are 12 facilities including product, material equipment, tool cabinet, assistant fixtures, etc. The schematic diagram of current facility layout is illustrated in Figure 2.

Due to the demand for enlarging production and improving production efficiency, a new aircraft assembly workshop will be invested. Four alternatives $A_{1}, A_{2}, A_{3}, A_{4}$ were generated by experts' teams from the aircraft industry, respectively. The quantitative features of each alternative are presented in Table 2.
Other qualitative features of the alternatives are determined by experts' team. However, selecting the best one among the four competing alternatives is too tricky. It is not apparent in the four options which alternative dominates others under various criteria and factors. Then four feasible alternatives are selected by DMs according to the final ranking. The procedures of the application case are given below.

4.1. Screen the Critical Criteria and Factors. An expert team was carefully formed with six chief engineers and six senior engineers from the aviation industry and six chief experts from the aviation research institution to determine criteria and factors that have a significant impact on facility layout in aircraft assembly workshop. Five criteria and twentythree factors were firstly collected by the first Delphi survey. These reduce to four criteria and fourteen factors by the second rounds of Delphi analysis. Each factor with its corresponding CV and CVR values are shown in Table 3. The CV values of factors are less than or equal to 0.5 and the CVR values of factors exceed 0.29 , which meet the factors retention requirement and reach the consensus between experts. The reason for further eliminating some criteria or factors is that they have the similarity function with other criteria or factors. The remaining criteria and factors help DM select the most suitable facility layout alternative. Table 3 shows the determined four criteria and fourteen factors that have a significant influence on the facility layout. The detail description of these criteria is given below:

(a) Space utilization (SU): the production space involves all production activities such as work in process inventories, material storage, and assembly product area, etc. The production space is classified as valueadded space and nonvalue added space [50]. This criterion consists of two factors as presented in Table 3.

(b) Transportation performance (TP): transportation performance has a significant influence on production, especially in saving costs and improving production efficiency. For example, to save the material handling costs and improve efficiency, it is vital to place the facilities with the closest material handling relationship adjacent to each other and decrease the delivery frequency. This criterion contains four factors as shown in Table 3.

(c) Layout flexibility (LF): the LF factors can be considered from three aspects: expansion flexibility, production flexibility, and material handling flexibility [24, 50]. For example, the easy expansion represents the robust capability to market fluctuation and demands disturbances, which involves adding new processes and installing new equipment according to the costs [51]. Production flexibility represents the robust capability to maintain production when facing product quality failures, material scarcity, sudden 


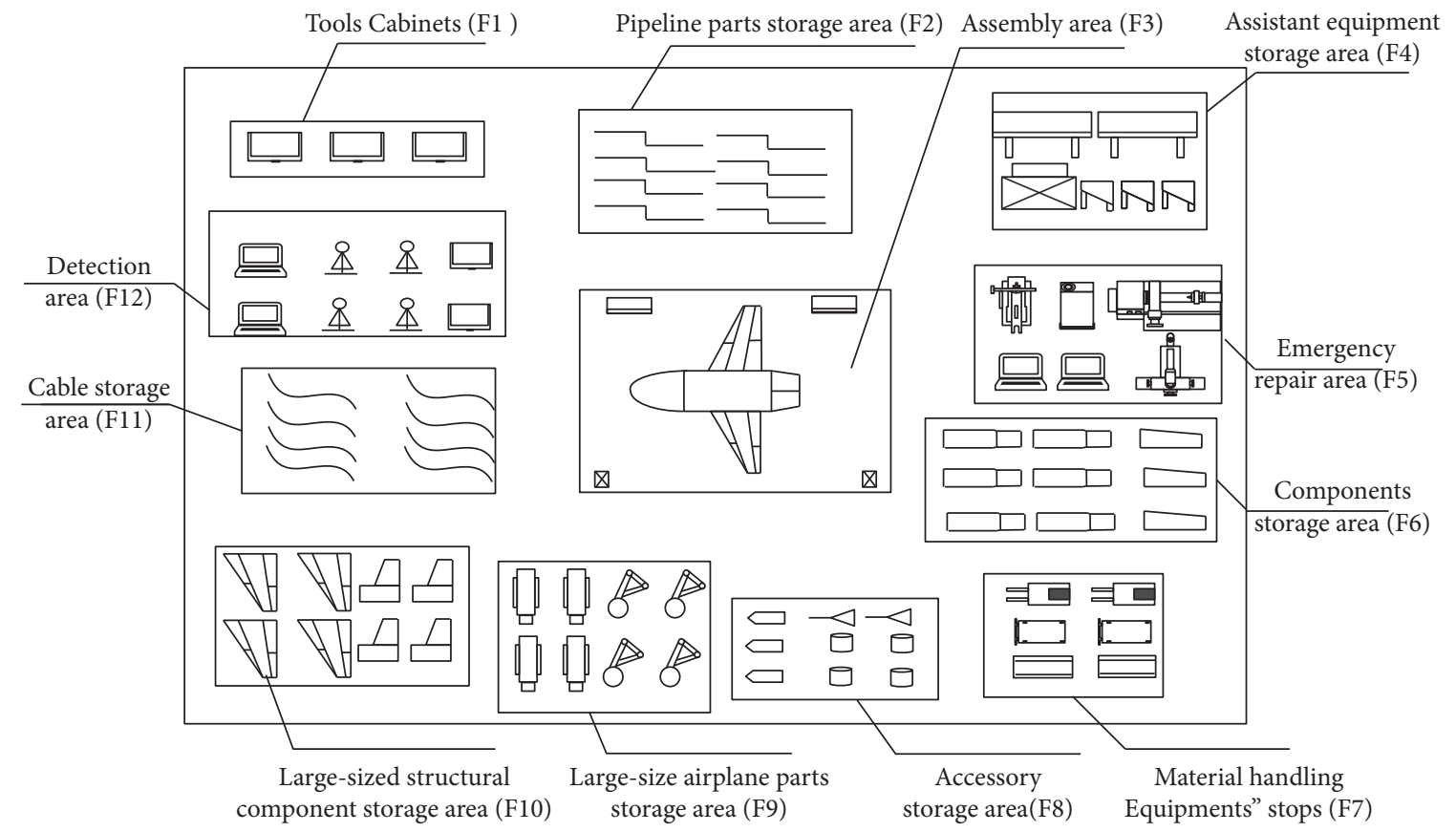

FIgURE 2: The schematic diagram of current facility layout.

TABLE 2: Alternatives' characteristics.

\begin{tabular}{lcccc}
\hline Characteristics & $A_{1}$ & $A_{2}$ & $A_{3}$ & $A_{4}$ \\
\hline Total area $\left(\mathrm{m}^{2}\right)$ & 2010.4 & 2010.4 & 2010.4 & 2010.4 \\
Total utilized area $\left(\mathrm{m}^{2}\right)$ & 1212.3 & 1235.2 & 1228.3 & 1240.6 \\
Total free area $\left(\mathrm{m}^{2}\right)$ & 798.1 & 775.2 & 782.1 & 769.8 \\
Value added area $\left(\mathrm{m}^{2}\right)$ & 871.6 & 901.4 & 924.2 & 941.7 \\
Non-value added area $\left(\mathrm{m}^{2}\right)$ & 340.7 & 333.8 & 304.1 & 298.9 \\
Transportation distance $\left(\mathrm{m}^{2}\right)$ & 1860 & 1650 & 1390 & 1460 \\
Material demand delivery & 95 & 98 & 110 & 102 \\
Material handling costs & 176,700 & 161,700 & 154,000 & 150,920 \\
(unit cost) & 28 & 25 & 21 & 21 \\
Equipment flow & 396.7 & 440.5 & 387.8 & 412.4 \\
Remaining useable space $\left(\mathrm{m}^{2}\right)$ & & 11 & 9 & 8 \\
The number of alternate & 9 & & & 38 \\
routes & 40 & 35 & 38 & 35 \\
Personnel flow & & & &
\end{tabular}

fault, etc. Material handling flexibility [24] reflects the capability of transportation equipment (i.e., AGV, forklift, trailer) to deliver various components with optional multiple paths between different facilities [24]. This criterion includes four factors as listed in Table 3.

(d) Personnel issue (PI): such as human safety, ergonomics, ease of supervision and control, and personnel flow should not be neglected in the factors analysis of facility layout selection due to their direct influence on the performance of production systems [24]. This criterion contains four factors as shown in Table 3.

4.2. Calculate the Subjective Weight. The relation between factors of different criteria is analyzed by using the FA method, and the network structure is formed and shown in Figure 3.
Pairwise comparisons are conducted on the example to demonstrate the dependencies by using TFN with scale in Table 1. Table 4 shows an example of a criteria LF concerning factor SU1. The rest of the evaluation is obtained in the same manner. According to equations (2) (4), the relative importance weights are obtained. For example, the priority vector of criteria LF regarding factor SU1 is also shown in Table 4. The other priority vectors of different criteria concerning factors are obtained in the same manner. After checking the consistency ratio by using equations (5) and (6) (less than 0.10 ), the comparison results are acceptable. These priorities all obtained by FA formed the submatrices of the supermatrix. Table 5 shows the initial supermatrix of the study. After that, each column of the initial supermatrix is normalized, and then it raised to power 20 to obtain the subjective weight of each factor $W$ as shown in Table 5.

4.3. Calculate the Objective Weight and Combination Weight. After linguistic evaluations on each factor concerning alternatives, the experts' evaluations are aggregated and then defuzzified by using equation (4) as shown in Table 6 . The objective weight $W^{\prime}$ of each factor can be obtained by equations (7)-(9) as shown in Table 6. The greater the weight, the more information about the DMs' preference that the factor contains. The weight coefficient $\alpha$ between subjective weight and objective weight is set at 0.5 in this paper. After that, the synergy of two kinds of weights is obtained by using equation (12). It will be used in the PROMETHEE II method later.

4.4. Obtain Ranking Order of Alternatives. The evaluation of each alternative in the PROMETHEE II approach is judged by experts directly. The deviation value of alternatives 
TABLE 3: Critical criteria and factors determination and explanation.

\begin{tabular}{|c|c|c|c|c|c|}
\hline Criteria & Factors & Description & $\mathrm{CV}$ & CVR & Reference \\
\hline \multirow{2}{*}{ Space utilization (SP) } & Value-added space (SP1) & $\begin{array}{l}\text { The value-added production activities are implemented in the } \\
\text { productive space. }\end{array}$ & 0.23 & 0.76 & \\
\hline & $\begin{array}{l}\text { Non-value-added space } \\
\text { (SP2) }\end{array}$ & $\begin{array}{l}\text { The non-value-added production activities are implemented } \\
\text { in the productive space. }\end{array}$ & 0.15 & 0.38 & \\
\hline \multirow{4}{*}{$\begin{array}{l}\text { Transportation } \\
\text { performance (TP) }\end{array}$} & $\begin{array}{l}\text { Transportation distance } \\
\text { (TP1) }\end{array}$ & $\begin{array}{l}\text { The distance of material transportation between different } \\
\text { facilities. }\end{array}$ & 0.20 & 0.42 & \multirow{4}{*}[6]{} \\
\hline & $\begin{array}{l}\text { Material demand delivery } \\
\text { (TP2) }\end{array}$ & $\begin{array}{c}\text { The frequency of material transportation between different } \\
\text { facilities. }\end{array}$ & 0.19 & 0.59 & \\
\hline & Information flow (TP3) & $\begin{array}{c}\text { Communication level between facilities can be used as a } \\
\text { surrogate for information flow. }\end{array}$ & 0.33 & 0.63 & \\
\hline & Equipment flow (TP4) & $\begin{array}{l}\text { The intensity of material handling equipment is used for } \\
\text { transportation in both facilities. }\end{array}$ & 0.11 & 0.57 & \\
\hline \multirow{4}{*}{ Layout flexibility (LF) } & Easy expansion (LF1) & $\begin{array}{l}\text { The ability of improvement of current production involves } \\
\text { add new processes and install new equipment according to the } \\
\text { costs. }\end{array}$ & 0.30 & 0.49 & \multirow{4}{*}[24]{} \\
\hline & $\begin{array}{l}\text { Remaining usable space } \\
\text { (LF2) }\end{array}$ & $\begin{array}{l}\text { The remaining available space with regular shape will be used } \\
\text { for future renovation of workshop and production line. }\end{array}$ & 0.27 & 0.34 & \\
\hline & $\begin{array}{l}\text { Multiple alternate routes } \\
\text { options (LF3) }\end{array}$ & $\begin{array}{l}\text { The options to assembly a component or a cluster of } \\
\text { components in adjusting the process and reprogram process. }\end{array}$ & 0.23 & 0.67 & \\
\hline & $\begin{array}{l}\text { Material handling } \\
\text { flexibility (LF4) }\end{array}$ & $\begin{array}{c}\text { The ability of transportation equipment (i.e., AGV, forklift, } \\
\text { and trailer) to delivery various components and materials with } \\
\text { optional multiple paths between different facilities. }\end{array}$ & 0.16 & 0.56 & \\
\hline \multirow{4}{*}{ Personnel issue (PI) } & Safety (PI1) & The safety for machines and employees. & 0.13 & 0.77 & \multirow{4}{*}[24,50]{} \\
\hline & $\begin{array}{l}\text { Maneuverability and } \\
\text { comfort (PI2) }\end{array}$ & $\begin{array}{c}\text { It considers maneuverable space and ergonomic for } \\
\text { employees. }\end{array}$ & 0.24 & 0.45 & \\
\hline & $\begin{array}{l}\text { Easy supervision and } \\
\text { control (PI3) }\end{array}$ & $\begin{array}{l}\text { It monitors and controls the entire workshop according to the } \\
\text { work efficiency of the employees and machines, the utilization } \\
\text { of personnel. }\end{array}$ & 0.22 & 0.47 & \\
\hline & Personnel flow (PI4) & $\begin{array}{c}\text { The intensity of employees that carry out work between } \\
\text { different facilities. }\end{array}$ & 0.22 & 0.49 & \\
\hline
\end{tabular}

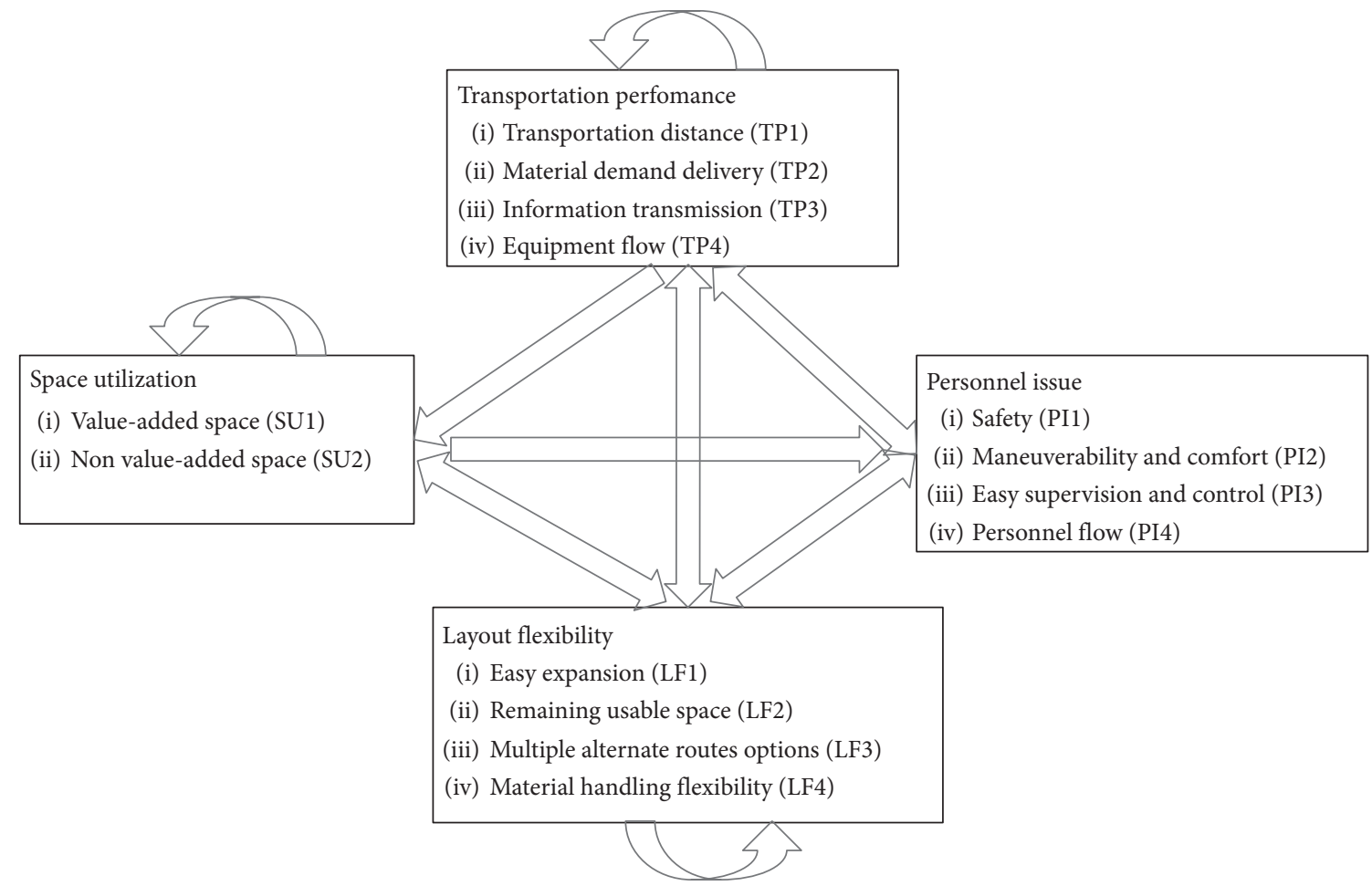

FIGURE 3: The network structure of criteria and factor. 
TABLE 4: Pairwise comparison matrix for criteria LF regarding the factor SU1 and priority vector.

\begin{tabular}{lccccc}
\hline Factors & LF1 & LF2 & LF3 & LF4 & Priority vector \\
\hline LF1 & $(1,1,1)$ & $(0.6,0.7,0.8)$ & $(1 / 0.8,1 / 0.7,1 / 0.6)$ & $(1 / 0.8,1 / 0.7,1 / 0.6)$ & 0.26 \\
LF2 & $(1 / 0.8,1 / 0.7,1 / 0.6)$ & $(1,1,1)$ & $(1 / 0.6,1 / 0.5,1 / 0.4)$ & $(1 / 0.7,1 / 0.6,1 / 0.5)$ & 0.34 \\
LF3 & $(0.6,0.7,0.8)$ & $(0.4,0.5,0.6)$ & $(1,1,1)$ & $(1 / 0.8,1 / 0.7,1 / 0.6)$ \\
LF4 & $(0.6,0.7,0.8)$ & $(0.5,0.6,0.7)$ & $(0.6,0.7,0.8)$ & $(1,1,1)$ & 0.20 \\
\hline
\end{tabular}

TABLE 5: Initial supermatrix and the weights of each factor.

\begin{tabular}{|c|c|c|c|c|c|c|c|c|c|c|c|c|c|c|c|}
\hline Factors & SU1 & SU2 & TP1 & TP2 & TP3 & TP4 & LF1 & LF2 & LF3 & LF4 & PI1 & PI2 & PI3 & PI4 & $W$ \\
\hline SU1 & 0.47 & 0.57 & 0.00 & 0.00 & 0.00 & 0.00 & 1.00 & 0.5 & 1.00 & 1.00 & 0.00 & 0.00 & 0.00 & 1.00 & 0.092 \\
\hline SU2 & 0.53 & 0.43 & 0.00 & 0.00 & 0.00 & 0.00 & 0.00 & 0.5 & 0.00 & 0.00 & 0.00 & 0.00 & 0.00 & 0.00 & 0.031 \\
\hline ТP1 & 0.38 & 0.35 & 0.09 & 0.12 & 0.15 & 0.15 & 0.00 & 0.33 & 0.02 & 0.03 & 0.00 & 0.00 & 0.00 & 0.00 & 0.042 \\
\hline TP2 & 0.15 & 0.13 & 0.19 & 0.16 & 0.27 & 0.29 & 0.00 & 0.10 & 0.34 & 0.24 & 0.00 & 0.00 & 0.00 & 0.14 & 0.054 \\
\hline TP3 & 0.27 & 0.24 & 0.36 & 0.34 & 0.22 & 0.37 & 1.00 & 0.12 & 0.23 & 0.35 & 0.27 & 0.35 & 1.00 & 0.36 & 0.133 \\
\hline ТP4 & 0.20 & 0.29 & 0.36 & 0.38 & 0.36 & 0.20 & 0.00 & 0.00 & 0.00 & 0.00 & 0.73 & 0.65 & 0.00 & 0.50 & 0.113 \\
\hline LF1 & 0.26 & 0.33 & 0.00 & 0.00 & 0.00 & 0.00 & 0.20 & 0.31 & 0.25 & 0.26 & 0.04 & 0.20 & 0.00 & 0.10 & 0.034 \\
\hline LF2 & 0.34 & 0.27 & 1.00 & 0.00 & 0.00 & 0.00 & 0.00 & 0.22 & 0.28 & 0.28 & 0.64 & 0.41 & 0.00 & 0.25 & 0.082 \\
\hline LF3 & 0.20 & 0.22 & 0.00 & 0.50 & 0.00 & 0.43 & 0.28 & 0.25 & 0.21 & 0.28 & 0.12 & 0.14 & 0.00 & 0.27 & 0.060 \\
\hline LF4 & 0.19 & 0.18 & 0.00 & 0.50 & 0.00 & 0.24 & 0.24 & 0.22 & 0.26 & 0.18 & 0.21 & 0.25 & 0.00 & 0.38 & 0.057 \\
\hline PI1 & 0.00 & 0.00 & 0.03 & 0.01 & 0.28 & 0.27 & 0.06 & 0.03 & 0.34 & 0.30 & 0.15 & 0.23 & 0.24 & 0.27 & 0.064 \\
\hline PI2 & 0.00 & 0.00 & 0.04 & 0.06 & 0.12 & 0.21 & 0.04 & 0.06 & 0.22 & 0.25 & 0.36 & 0.21 & 0.34 & 0.32 & 0.060 \\
\hline PI3 & 0.00 & 0.00 & 0.28 & 0.42 & 0.45 & 0.32 & 0.43 & 0.12 & 0.10 & 0.07 & 0.22 & 0.27 & 0.14 & 0.25 & 0.084 \\
\hline PI4 & 0.00 & 0.00 & 0.65 & 0.51 & 0.15 & 0.20 & 0.47 & 0.79 & 0.34 & 0.38 & 0.28 & 0.29 & 0.28 & 0.16 & 0.094 \\
\hline
\end{tabular}

TABLE 6: Evaluation of each factor.

\begin{tabular}{lccccc}
\hline Factors & $A_{1}$ & $A_{2}$ & $A_{3}$ & $A_{4}$ & $W^{\prime}$ \\
\hline SU1 & 0.65 & 0.48 & 0.52 & 0.66 & 0.099 \\
SU2 & 0.52 & 0.59 & 0.53 & 0.54 & 0.013 \\
TP1 & 0.51 & 0.56 & 0.67 & 0.52 & 0.064 \\
TP2 & 0.67 & 0.51 & 0.62 & 0.52 & 0.071 \\
TP3 & 0.53 & 0.71 & 0.63 & 0.69 & 0.065 \\
TP4 & 0.56 & 0.81 & 0.62 & 0.63 & 0.103 \\
LF1 & 0.52 & 0.61 & 0.81 & 0.75 & 0.153 \\
LF2 & 0.62 & 0.61 & 0.81 & 0.68 & 0.070 \\
LF3 & 0.70 & 0.64 & 0.66 & 0.66 & 0.006 \\
LF4 & 0.83 & 0.65 & 0.81 & 0.62 & 0.087 \\
PI1 & 0.48 & 0.52 & 0.68 & 0.53 & 0.096 \\
PI2 & 0.44 & 0.57 & 0.43 & 0.51 & 0.070 \\
PI3 & 0.48 & 0.52 & 0.52 & 0.62 & 0.048 \\
PI4 & 0.69 & 0.65 & 0.52 & 0.63 & 0.055 \\
\hline
\end{tabular}

regarding a factor is calculated using equation (10). Then the preference function is assigned with the criteria selected by the Delphi method in terms of its different features as shown in Table 7.

For example, SU1 is a typical quantitative criterion with linear preference up to a preference threshold. Therefore, the preference function of criterion SU1 is assigned with $\mathrm{V}$ shape. LF1 is a qualitative criterion with a fixed preference threshold, so the preference function of criterion LF1 is assigned with $\mathrm{U}$ shape. Furthermore, PI1 is a qualitative criterion without assigning importance for the difference between criteria value. The preference function of criterion PI1 is assigned with the Usual criterion. Moreover, the thresholds are set by the results agreed by the expert's team as shown in Table 7. The aggregated preference functions are obtained using equation (11) and the two kinds of weights are synthesized by equation (12), which obtained from the FA and entropy approach previously.

Finally, the positive, negative, and the NF of alternatives are obtained using equations (13) and (14). Table 8 shows the results of positive, negative, NFs, and final ranking. The higher the NFs, the better alternative, and the lower the NFs, the worse alternative. Therefore, alternative $A_{3}$ with the highest NF value 0.227 is regarded as the optimal alternative. The alternative $A_{4}$ is followed by an alternative $A_{3}$ with an NF value of 0.128 . The alternative $A_{2}$ is considered as the third choice for DMs with a NF value of -0.055 while the alternative $A_{1}$ with the lowest NF value -0.300 is considered as the worst alternative.

\section{Discussion}

5.1. Comparison Analysis. To further verify the validity of the proposed approach, the FANP method [15], the Fuzzy TOPSIS (FTOPSIS) [51], and gained and lost dominance score method (GLDS) method [53, 54] are used to rank alternatives for comparison. Meanwhile, to reflect the performance of the combined weight, the subjective weight alone $(\alpha=1)$ and the objective weight alone $(\alpha=0)$ are also considered, respectively. Table 9 shows the ranking comparison of all alternatives as obtained by the above methods.

5.1.1. Compared with FANP. To guarantee an unbiased comparison, the same experts evaluate each alternative that was also used in the PROMETHEE method. The subjective weights $W$ of each factor are also obtained from Table 5. The total scores of each alternative are obtained by multiplying the weights of each factor by the priority vectors of each alternative, and then the outcomes of each alternative are 
Table 7: Preference function for each criterion.

\begin{tabular}{llccc}
\hline Criteria & Type & Units & Preference function \\
\hline SU1 & Quantitative & Square meter & V-shaped \\
SU2 & Quantitative & Square meter & V-shaped \\
TP1 & Quantitative & Meter & V-shaped \\
TP2 & Quantitative & Times & V-shaped \\
TP3 & Qualitative & - & U-shaped \\
TP4 & Quantitative & Number of equipment & V-shaped \\
LF1 & Qualitative & - & U-shaped \\
LF2 & Quantitative & Number of remaining usable space & V-shaped \\
LF3 & Quantitative & Number of alternate route options & 0.10 \\
LF4 & Qualitative & - & V-shaped \\
PI1 & Qualitative & - & U-shaped \\
PI2 & Qualitative & - & Usual criterion \\
PI3 & Qualitative & - & U-shaped \\
PI4 & Quantitative & Uumber of personnel & 0.05 \\
\hline
\end{tabular}

TABLE 8: The rank of alternatives with leaving entering and NFs.

\begin{tabular}{lcccc}
\hline Alternatives & Positive flow & Negative flow & Net flow & Ranking \\
\hline$A_{1}$ & 0.203 & 0.503 & -0.300 & 4 \\
$A_{2}$ & 0.356 & 0.411 & -0.055 & 3 \\
$A_{3}$ & 0.472 & 0.244 & 0.227 & 1 \\
$A_{4}$ & 0.401 & 0.273 & 0.128 & 2 \\
\hline
\end{tabular}

summed. As shown in Table 9, alternative $A_{4}$ gains the highest total scores of 0.64 , followed by alternatives $A_{3}, A_{2}$, and $A_{1}$ with the total scores (TS) of $0.62,0.60$, and 0.58 , respectively. Therefore, it can be concluded that the ranking order obtained by the FANP method is $A_{4}>A_{3}>A_{2}>A_{1}$. As shown in Table 9, the FANP and the proposed method using the subjective weight obtain the same final ranking. In Table 9, the alternative $A_{4}$ is the optimal alternative with the highest total score while the alternative $A_{1}$ is the worst alternative for the lowest total score. Similarly, in the proposed method with using the subjective weight $(\alpha=1)$ alone, alternative $A_{1}$ is the worst with the lowest NF values while the alternative $A_{4}$ is the best with the highest NF values. The main reason why the two methods get the same ranking orders is that they apply a common subjective weight separately to the evaluation of alternatives.

5.1.2. Compared with Different Weight Coefficients in the Proposed Method. Table 9 shows the rank of alternatives by using subjective weight $(\alpha=1)$ alone. The ranking priority order is $A_{4}>A_{3}>A_{2}>A_{1}$, while in the separate objective weight $(\alpha=0)$, the ranking priority order is $A_{3}>A_{4}>A_{2}>A_{1}$. Although both weights can be used to rank alternatives, separate consideration of subjective or objective weights generates a different ranking order and may lead to a poor decision. For example, alternative $A_{3}$ is the second choice for DMs using subjective weight. At the same time, alternative $A_{3}$ is the best selection for DMs using objective weight. Moreover, when weighting coefficients are set as 0.5 ( $\alpha=0.5$ ), ranking order is the same as using separate objective weight $(\alpha=0)$ that shown in Table 9. The robustness of the proposed method is further verified despite the variation in coefficient of objective weight. It can be concluded that setting an appropriate weight coefficient $\alpha$ based on the practical situation and DMs opinion has an impact on the final ranking and following reasonable planning.

5.1.3. Compared with the FTOPSIS. Based on the modified digital logic (MDL) approach [55], the weights of factors can be obtained $w_{m}=(0.095,0.031,0.045,0.050,0.125,0.115$, $0.032,0.073,0.055,0.050,0.081,0.073,0.080,0.095)^{T}$. In line with the procedure of the TOPSIS method, the distance from given alternatives to positive and negative ideal solutions can be obtained as $d^{+}=(0.234,0.180,0.188,0.127)$, $d^{-}=(0.159,0.196,0.160,0.211)$, respectively. Then the relative closeness (RC) can be obtained 0.404, 0.522, 0.459, and 0.624. The ranking order of the FTOPSIS method is $A_{4}>A_{2}>A_{3}>A_{1}$ as shown in Table 9, which is different from that obtained by the proposed method. The main reasons leading to difference are as follows. Firstly, different weight calculation exists between in FTOPSIS; the MDL method is one of the subjective weight calculation methods but ignores independence between factors. Secondly, different normalization is used to eliminate the units and dimensions for the criterion function. The TOPSIS uses vector normalization while PROMETHEE allows for conflicting criteria with different dimensions and units without normalization $[45,54]$. Furthermore, using vector normalization would increase the risk of information distortion [11]. Lastly, the mechanism of both methods is remarkably different. PROMETHEE assigns the different preference functions based on the feature of factors and integrates the positive flow and negative flow based on possibility degree function [53]. The TOPSIS method makes evaluation using the same preference function and calculates distance between alternatives and the positive ideal solution and negative ideal solution, respectively $[22,54]$.

5.1.4. Compared with ANP-GLDS and CW-GLDS Methods. Compared with the classical GLDS method, the weights of factors in this paper are obtained by FANP and FANP-Entropy, respectively. Therefore, the ANP-GLDS and CW-GLDS 
TABLE 9: Ranking comparison between proposed method with other FMCDM methods.

\begin{tabular}{lccccccccccccc}
\hline & \multicolumn{2}{c}{ Proposed } & \multicolumn{2}{c}{ Proposed } & \multicolumn{2}{c}{ FANP } & \multicolumn{2}{c}{ FTOPSIS } & \multicolumn{2}{c}{ ANP-GLDS } \\
Alteratives & \multicolumn{2}{c}{ method $(\alpha=1)$} & \multicolumn{2}{c}{ method $(\alpha=0)$} & \multicolumn{2}{c}{ CW-GLDS } \\
& NF & Rank & NF & Rank & TS & Rank & RC & Rank & CS & Rank & CS & Rank \\
\hline$A_{1}$ & -0.245 & 4 & -0.355 & 4 & 0.580 & 4 & 0.404 & 4 & -0.043 & 4 & -0.042 & 4 \\
$A_{2}$ & 0.001 & 3 & -0.109 & 3 & 0.601 & 3 & 0.522 & 2 & -0.020 & 3 & -0.019 & 3 \\
$A_{3}$ & 0.088 & 2 & 0.367 & 1 & 0.620 & 2 & 0.459 & 3 & 0.036 & 2 & 0.139 & 1 \\
$A_{4}$ & 0.158 & 1 & 0.098 & 2 & 0.641 & 1 & 0.624 & 1 & 0.142 & 1 & 0.038 & 2 \\
\hline
\end{tabular}

are considered to compare with the proposed methods. According to the decision matrix and subjective weights of factors, the overall gained dominance score and overall lost dominance score of alternatives in ANP-GLS can be obtained odgs $_{\text {sub }}=(0.461,0.720,0.968,1.302)$, olds $_{\text {sub }}=(0.0800 .058$, $0.048,0.042)$. Similarly, the overall gained dominance score and overall lost dominance score of alternatives in CW-GLS can be obtained odgs $\mathrm{cw}_{\mathrm{cw}}=(0.583,0.935,1.67,1.26)$, olds $\mathrm{cw}_{\mathrm{cw}}=$ (0. 047, 0.034, 0.025, 0.028). Based on the GLDS method [54], the collective score (CS) of ANP-GLDS and CW-GLDS are shown in Table 9, respectively. The ANP-GLDS method obtains the same ranking order with the proposed method $(\alpha=1)$. The CW-GLDS method also gets the same rank results with the proposed method $(\alpha=0)$, which further verify the effectiveness of the proposed method. In this case, it is essential and relatively difficult for classifying the criterion into benefit criterion and cost criterion in the GLDS method especially with the number of factors increased and some neutral factors (i.e., expand flexibility, production flexibility, material handling flexibility, etc.)

On the other hand, the features of alternatives also reflect the ranking results to some extent. Table 2 shows alternative $A_{4}$ with maximum value-added space, minimum material handling costs, and minimum personnel flow. Besides, because of minimum equipment flow and equilibration overall performance, the alternative $A_{3}$ is also regarded as a good choice of DMs. Though alternative $A_{2}$ has a maximum remaining usable space, and the maximum number of alternate routes, owing to the poor performance in criteria value-added space, transportation distance, material demand delivery, and equipment flow, it is considered as the third choice of decision-makers. Additionally, because of bad performance in criteria value-added space, transportation distance, material demand, equipment flow, and personnel flow, the alternative $A_{1}$ is regarded as the worst layouts. Table 2 also presents the gap of characteristics among four alternatives in quantitative factors (i.e., valueadded space, transportation distance, equipment flow, personnel flow). For example, the alternative $A_{4}$ has $941.7 \mathrm{~m}^{2}$ value-added area as compared to $871.6 \mathrm{~m}^{2}$ in the alternative $A_{1}$. The alternative $A_{4}$ has 150,920 material handling cost as compared to 176,700 in the alternative $A_{1}$. Additionally, the gap of characteristics among four alternatives in qualitative factors is evaluated by experts.

5.2. Sensitivity Analysis. Sensitivity analysis provides strategical insights into the evaluation results of the case application. As mentioned above, the subjective weights result from a series of pairwise comparisons and largely depend on experts' subjective assessments. The objective weights include the preference information about DMs. Both of them have an essential influence on the preference order and final decision. Given this, it is essential to analyze how the performance is influenced by the fluctuation of factors weight.

Figure 4 presents the sensitivity analysis for the several typical factors in the FA method. Other factors were the same trend. The weights of each factor are changed, and the total score of alternatives is varied with the $x$-axis indicating the weight of factor and the $y$-axis representing a total score of alternatives. Figure 4 shows alternative $A_{4}$ is the optimal alternative with the highest total score in selected factors while the alternative $A_{1}$ is the worst alternative for the lowest total score.

Figure 5 also shows that alternative $A_{1}$ is the worst for the negative values of NF. The alternative $A_{3}$ is the best for its higher value of NF over a wide range of factors. Therefore, the priority rank from FA and the proposed methods is verified again by sensitivity analysis. As the weight of factors increases, the total score is also increased as shown in Figure 4. However, there are some differences in the case of the proposed method. When the weight of factor is increased, the value of NF in alternatives may decrease as shown in Figure 5.

The main reason for the distinct results of the sensitivity analysis is that the different preference functions for each factor in the FA method have not been considered. It is illogical to ignore the influence of factors on the objective in a real case, and it may lead to poor decision-making in investment. Compared with the FA method, the proposed method is more valid since as the weight of factor that has a positive impact on decision goal is increased, the NF of alternative concerning factor will be incremental. For instance, the factor of LF1 has a positive impact on rapid response to the market fluctuation, and the NF of alternative $A_{3}$ increases with the weight raising as shown in Figure 5(e). Similarly, when the weight of factor that has a negative impact on decision goal is increased, the NF of alternative with respect to the factor will be decreased. For example, the factor SU2 has a negative impact on benefit and it should be decreased in weight assignment when DMs plan a facility layout. $\mathrm{s} \mathrm{A}_{3}$ is decreased in the proposed method. Additionally, the higher weight's factor that has a positive impact on decision goal (i.e., SU1, TP3, LF1) is considered to be worthy of the investment and further improvement. It is 

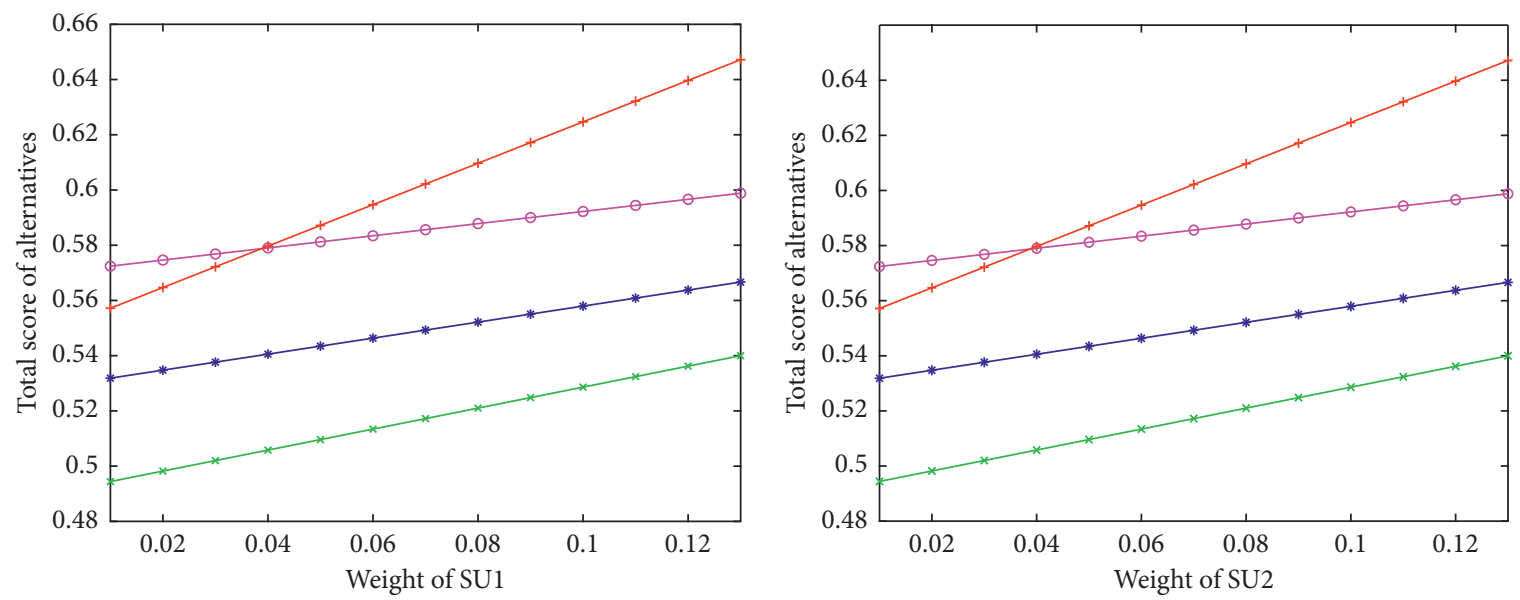

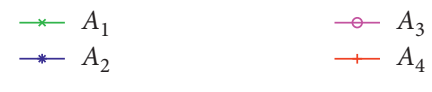

(a)

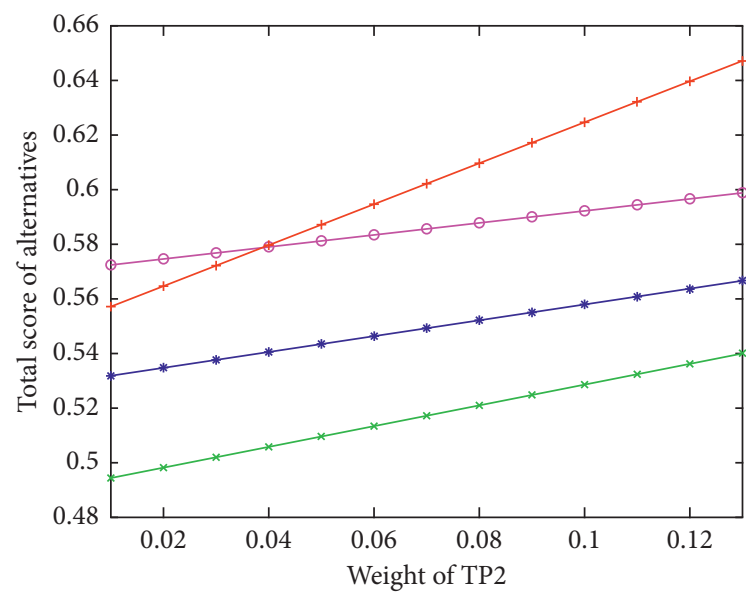

$$
\begin{array}{ll}
* A_{1} & -A_{3} \\
\rightarrow A_{2} & \div A_{4}
\end{array}
$$

(c)

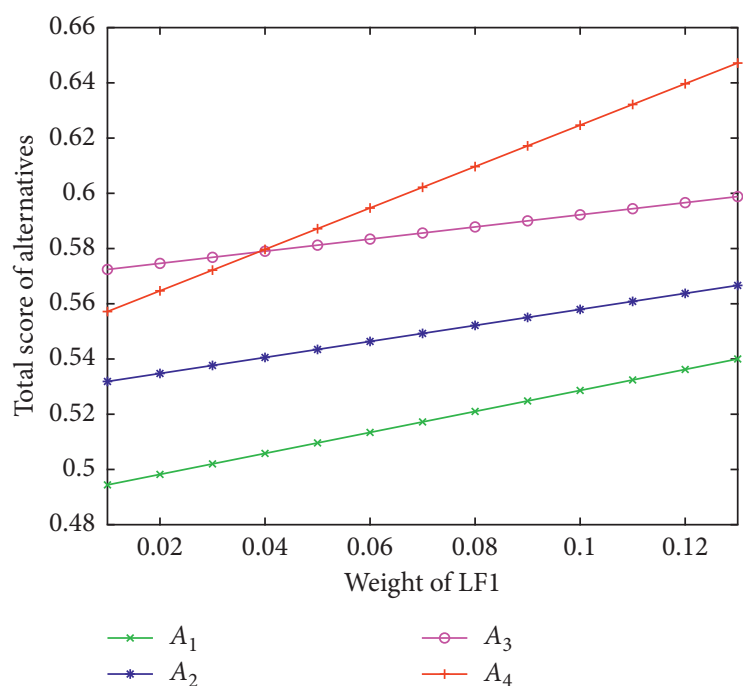

(e)

$$
\begin{array}{ll}
\rightarrow & A_{1} \\
\rightarrow-A_{2} & \rightarrow A_{3}
\end{array}
$$

(b)

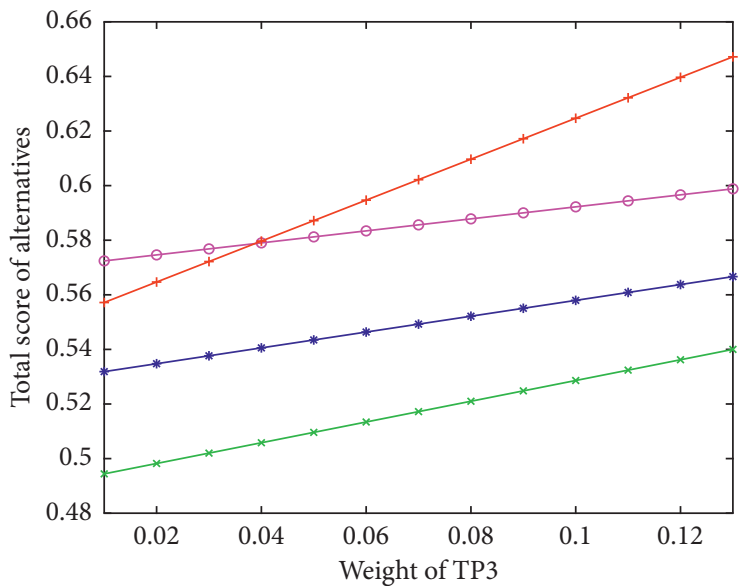

$$
\begin{array}{ll}
* A_{1} & -A_{3} \\
* A_{2} & \div A_{4}
\end{array}
$$

(d)

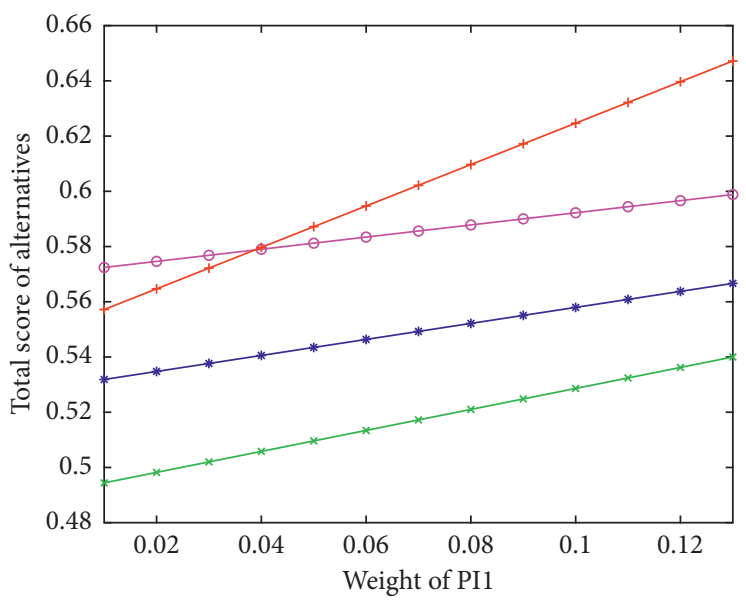

$$
\rightarrow A_{1} \quad \rightarrow A_{3}
$$

(f)

FIGURE 4: Sensitivity results for the representative factors: (a) SU1; (b) SU2; (c) TP2; (d) TP3; (e) LF1; (f) PI1 in the FA method. 

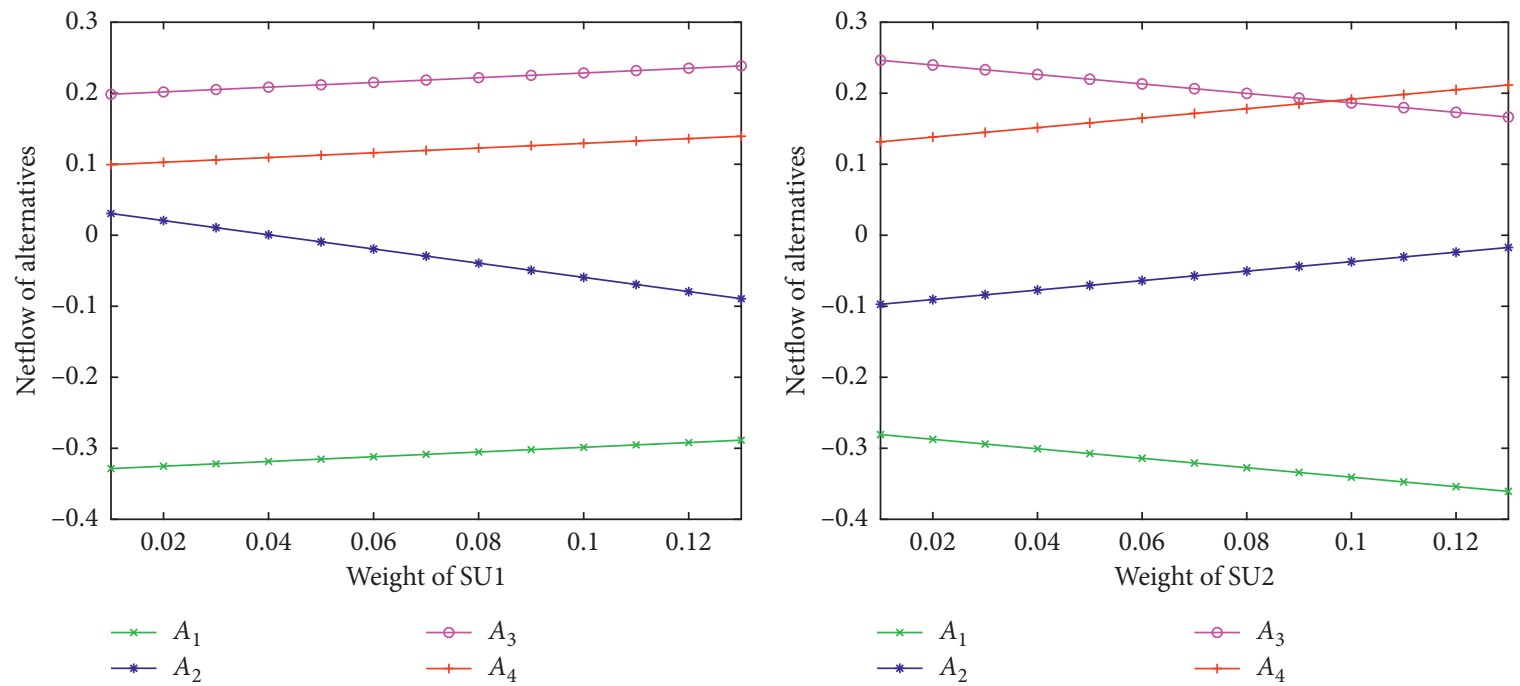

$\underset{*}{*} A_{1}$

$-A_{3}$

(a)

(b)
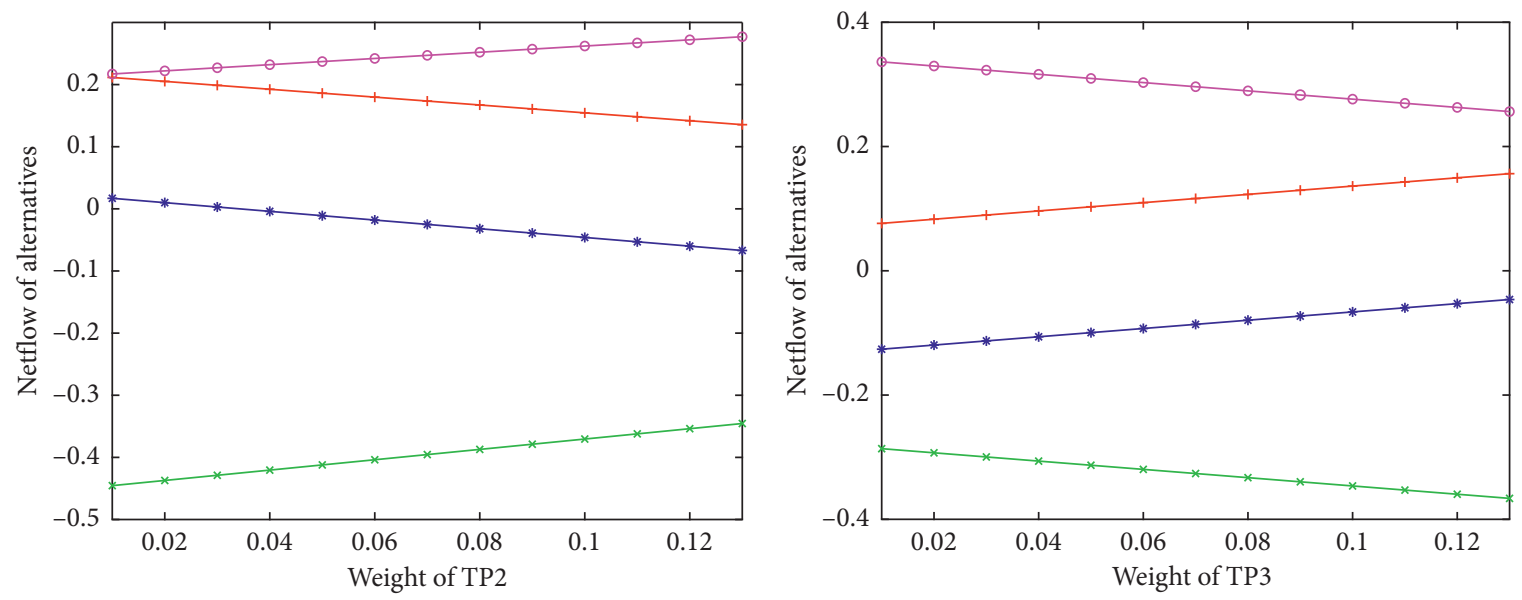

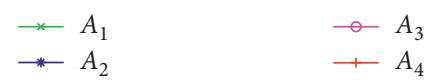

(c)

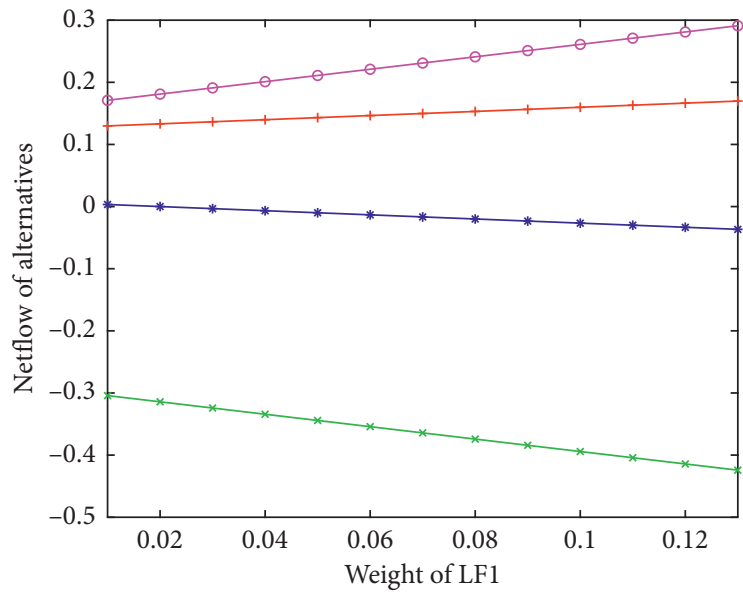

* $A_{1}$

$\rightarrow A_{2}$

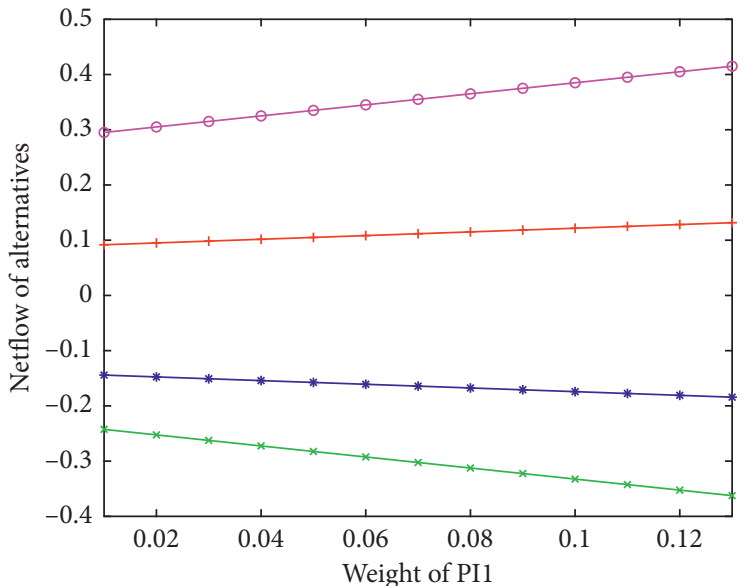

* $A_{1}$

$\rightarrow A_{2}$ $\circ A_{3}$

$\div A_{4}$

(d)

$$
\begin{array}{r}
\multimap \\
-A_{3} \\
-A_{4}
\end{array}
$$

(f)

FIGURE 5: Sensitivity results for the representative factors: (a) SU1; (b) SU2; (c) TP2; (d) TP3; (e) LF1; (f) PI1 in the proposed method $(\alpha=0.5)$. 
worth noting that changes in the weight range may lead to a different final rank. For example, as the weight increased, the $\mathrm{NF}$ of alternative $A_{4}$ may perform better than any other alternatives as shown in Figure 5(d). Therefore, the proposed method provided a more accurate and reasonable evaluation of facility layout selection in the manufacturing system. Moreover, it also presents the priority factor worthy of future improvement.

\section{Conclusions and Further Research}

The evaluation of facility layout alternatives in the manufacturing system is usually a throne problem with conflicting and uncertain factors and interactions relationship between numerous factors, which is usually solved by the DMs experience. This paper proposes a hybrid MCDM method with combined weight based on the integration of Delphi, fuzzy set theory, ANP, Entropy, and PROMETHEE II method to evaluate the facility layout alternatives in the manufacturing system. In the procedure of the proposed hybrid MCDM method, the Delphi method is used to screening the critical criteria and factors. Furthermore, FA and Entropy are applied for calculating the combined weights of each factor. The combined weights overcome the shortage of subjective weight and objective weight, which contribute to reflecting the essential features of decision-making problem and providing a more rational weight assignment. Finally, the fuzzy PROMETHEE II method helps DMs select the most appropriate alternatives in the final decision.

The application results reveal that the proposed hybrid MCDM method can be effectively applied in choosing the most suitable alternative for facility layout in an aircraft assembly workshop. Comparison analysis with some available methods shows that the weight has an impact on final ranking and verifies the robustness of the proposed method. Additionally, sensitivity analysis indicates that the proposed approach is more logical and rational than the FA method in a real case and provides managerial insights to identify the critical factors (i.e., SU1, TP3, LF1), which is worthy of the investment and future improvement. Therefore, the proposed method is a better choice for facility layout selection in the manufacturing system.

For future research, the proposed hybrid method may be considered to solve other complex MCDM problems in other fields. Furthermore, setting the weight coefficient may be optimized by the intelligent algorithm in the future study.

\section{Data Availability}

The data used to support the findings of this study are available from the corresponding author upon request.

\section{Conflicts of Interest}

The authors declare that there are no conflicts of interest regarding the publication of this paper.

\section{Acknowledgments}

This research was funded by the National Natural Science Foundation of China (grant no. 51575274) and National Defense Basic Scientific Research Project (grant no. JCKY2016605B006) (JCKY2016203B083).

\section{References}

[1] S. Zha, Y. Guo, S. Huang, F. Wang, and X. Huang, "Robust facility layout design under uncertain product demands," Procedia CIRP, vol. 63, pp. 354-359, 2017.

[2] H. Hosseini-Nasab, S. Fereidouni, S. M. T. Fatemi Ghomi, and M. B. Fakhrzad, "Classification of facility layout problems: a review study," The International Journal of Advanced Manufacturing Technology, vol. 94, no. 1-4, pp. 957-977, 2017.

[3] A. Hadi-Vencheh and A. Mohamadghasemi, "An integrated AHP-NLP methodology for facility layout design," Journal of Manufacturing Systems, vol. 32, no. 1, pp. 40-45, 2013.

[4] T. Ertay, D. Ruan, and U. Tuzkaya, "Integrating data envelopment analysis and analytic hierarchy for the facility layout design in manufacturing systems," Information Sciences, vol. 176, no. 3, pp. 237-262, 2006.

[5] L. Wang, X. Wang, J. Peng, and J. Wang, "The differences in hotel selection among various types of travellers: comparative analysis with a useful bounded rationality behavioural decision support model," Tourism Management, vol. 76, Article ID 103961, 2020.

[6] C.-N. Wang, V. Nguyen, D. Duong, and H. Thai, "A hybrid fuzzy analysis network process (FANP) and the technique for order of preference by similarity to ideal solution (TOPSIS) approaches for solid waste to energy plant location selection in Vietnam," Applied Sciences, vol. 8, no. 7, p. 1100, 2018.

[7] T. Yang and C. Kuo, "A hierarchical AHP/DEA methodology for the facilities layout design problem," European Journal of Operational Research, vol. 147, no. 1, pp. 128-136, 2003.

[8] H. Liao, X. Mi, Z. Xu, J. Xu, and F. Herrera, "Intuitionistic fuzzy analytic network process," IEEE Transactions on Fuzzy Systems, vol. 26, no. 5, pp. 2578-2590, 2018.

[9] H. Liao and Z. Xu, "Multi-criteria decision making with intuitionistic fuzzy PROMETHEE," Journal of Intelligent \& Fuzzy Systems, vol. 27, no. 4, pp. 1703-1717, 2014.

[10] P. Ji, H.-Y. Zhang, and J.-Q. Wang, "A projection-based outranking method with multi-hesitant fuzzy linguistic term sets for hotel location selection," Cognitive Computation, vol. 10, no. 5, pp. 737-751, 2018.

[11] H. Liao and X. Wu, "Comparison analysis between DNMA method and other MCDM methods," ICSES Transaction on Neural and Fuzzy Computing, vol. 2, no. 1, pp. 1-7, 2019.

[12] F. Çebi and İ. Otay, "Multi-criteria and multi-stage facility location selection under interval type-2 fuzzy environment: a case study for a cement factory," International Journal of Computational Intelligence Systems, vol. 8, no. 2, pp. 330-344, 2015.

[13] S. Altuntas, H. Selim, and T. Dereli, "A fuzzy DEMATELbased solution approach for facility layout problem: a case study," The International Journal of Advanced Manufacturing Technology, vol. 73, no. 5-8, pp. 749-771, 2014.

[14] H. Shokri, B. Ashjari, M. Saberi, and H. Y. Jin, “An integrated AHP.VIKOR methodology for facility layout design," Industrial Engineering and Management Systems, vol. 12, no. 4, pp. 40-45, 2013.

[15] A. Özdağoğlu, "A multi-criteria decision-making methodology on the selection of facility location: fuzzy ANP," The 
International Journal of Advanced Manufacturing Technology, vol. 59, no. 5-8, pp. 787-803, 2011.

[16] İ. Ertuğrul and N. Karakaşoğlu, "Comparison of fuzzy AHP and fuzzy TOPSIS methods for facility location selection," International Journal of Advanced Manufacturing Technology, vol. 39, no. 7-8, pp. 783-795, 2008.

[17] J. P. C. Luis, C. Dias, and J. N. Clímaco, "A parallel implementation of the PROMETHEE method," European Journal of Operational Research, vol. 104, no. 3, pp. 521-531, 1998.

[18] M. F. Bongo, K. M. S. Alimpangog, J. F. Loar, J. A. Montefalcon, and L. A. Ocampo, "An application of DEMATEL-ANP and PROMETHEE II approach for air traffic controllers' workload stress problem: a case of Mactan Civil Aviation Authority of the Philippines," Journal of Air Transport Management, vol. 68, pp. 198-213, 2018.

[19] M. Velasquez and P. T. Hester, "An analysis of multi-criteria decision making methods," International Journal of Operations Research, vol. 10, no. 2, pp. 56-66, 2013.

[20] S. Avikal, P. K. Mishra, and R. Jain, "A fuzzy AHP and PROMETHEE method-based heuristic for disassembly line balancing problems," International Journal of Production Research, vol. 52, no. 5, pp. 1306-1317, 2014.

[21] J. M. Brankovic, M. Markovic, and D. Nikolic, "Comparative study of hydraulic structures alternatives using promethee II complete ranking method," Water Resource Management, vol. 2018, no. 32, pp. 3457-3471, 2018.

[22] S. M. Mousavi, R. T. Moghaddam, M. Heydar et al., "Multicriteria decision making for plant location selection: an integrated delphi-AHP-PROMETHEE methodology," Arabian Journal for Science and Engineering, vol. 2013, no. 38, pp. 1255-1268, 2013.

[23] M. Hanine, O. Boutkhoum, T. Agouti, and A. Tikniouine, "A new integrated methodology using modified Delphi-fuzzy AHP-PROMETHEE for Geospatial Business Intelligence selection," Information Systems and E-Business Management, vol. 15, no. 4, pp. 897-925, 2017.

[24] T. Al-Hawari, A. Mumani, and A. Momani, "Application of the analytic network process to facility layout selection," Journal of Manufacturing Systems, vol. 33, no. 4, pp. 488-497, 2014.

[25] H. Jin, M. Zhang, and Y. Yuan, "Analytic network processbased multi-criteria decision approach and sensitivity analysis for temporary facility layout planning in construction projects," Applied Sciences, vol. 8, no. 12, p. 2434, 2018.

[26] G. Rowe and G. Wright, "The Delphi technique as a forecasting tool: issues and analysis," International Journal of Forecasting, vol. 15, no. 4, pp. 353-375, 1999.

[27] M. Kim, Y.-C. Jang, and S. Lee, "Application of Delphi-AHP methods to select the priorities of WEEE for recycling in a waste management decision-making tool," Journal of Environmental Management, vol. 128, no. 20, pp. 941-948, 2013.

[28] B. Zakaria, R. Abdullah, M. F. Ramli, and P. A. Latif, "Selection criteria using the Delphi method for siting an integrated hazardous waste disposal facility in Malaysia," Journal of Environmental Planning and Management, vol. 56, no. 4, pp. 512-530, 2013.

[29] F. Niederman, J. C. Brancheau, and J. C. Wetherbe, "Information systems management issues for the 1990s," Mis Quarterly, vol. 15, no. 4, pp. 475-500, 1991.

[30] R. Joshi, D. K. Banwet, and R. Shankar, "A Delphi-AHPTOPSIS based benchmarking framework for performance improvement of a cold chain," Expert Systems with Applications, vol. 38, no. 8, pp. 10170-10182, 2011.
[31] J. Ondrus, T. Bui, and Y. Pigneur, "A foresight support system using MCDM methods," Group Decision \& Negotiation, vol. 24, no. 2, pp. 1-26, 2014.

[32] M. Z. S. Jarir, S. Dajani, and W. K. Talley, "Stability and agreement criteria for the termination of Delphi studies," Technological Forecasting and Social Change, vol. 13, no. 1, pp. 83-90, 1979.

[33] F. R. Wilson, W. Pan, and D. A. Schumsky, "Recalculation of the critical values for Lawshe's content validity ratio," Measurement and Evaluation in Counseling and Development, vol. 45, no. 3, pp. 197-210, 2012.

[34] I. Emovon, R. A. Norman, and A. J. Murphy, "Hybrid MCDM based methodology for selecting the optimum maintenance strategy for ship machinery systems," Journal of Intelligent Manufacturing, vol. 29, no. 3, pp. 519-531, 2015.

[35] S. Tadić, S. Zečević, and M. Krstić, "A novel hybrid MCDM model based on fuzzy DEMATEL, fuzzy ANP and fuzzy VIKOR for city logistics concept selection," Expert Systems with Applications, vol. 41, no. 18, pp. 8112-8128, 2014.

[36] T. Chaira and A. K. Ray, "A new measure using intuitionistic fuzzy set theory and its application to edge detection," Applied Soft Computing, vol. 8, no. 2, pp. 919-927, 2008.

[37] S. Önüt, S. S. Kara, and E. Işik, "Long term supplier selection using a combined fuzzy MCDM approach: a case study for a telecommunication company," Expert Systems with Applications, vol. 36, no. 2, pp. 3887-3895, 2009.

[38] U. R. Tuzkaya and S. Önüt, “A fuzzy analytic network process based approach to transportation-mode selection between Turkey and Germany: a case study," Information Sciences, vol. 178, no. 15, pp. 3133-3146, 2008.

[39] S. Vinodh, T. S. Sai Balagi, and A. Patil, "A hybrid MCDM approach for agile concept selection using fuzzy DEMATEL, fuzzy ANP and fuzzy TOPSIS," The International Journal of Advanced Manufacturing Technology, vol. 83, no. 9-12, pp. 1979-1987, 2015.

[40] A. A. Bazzazi, M. Osanloo, and B. Karimi, "Deriving preference order of open pit mines equipment through MADM methods: application of modified VIKOR method," Expert Systems with Applications, vol. 38, no. 3, pp. 2550-2556, 2011.

[41] S. Chen, Y. Leng, B. Mao, and S. Liu, "Integrated weight-based multi-criteria evaluation on transfer in large transport terminals: a case study of the Beijing South Railway Station," Transportation Research Part A: Policy and Practice, vol. 66, no. 1, pp. 13-26, 2014.

[42] H. Zhang and L. Yu, "MADM method based on cross-entropy and extended TOPSIS with interval-valued intuitionistic fuzzy sets," Knowledge-Based Systems, vol. 30, no. 2, pp. 115-120, 2012.

[43] N. Kalogeras, G. Baourakis, C. Zopounidis, and G. van Dijk, "Evaluating the financial performance of agri-food firms: a multicriteria decision-aid approach," Journal of Food Engineering, vol. 70, no. 3, pp. 365-371, 2005.

[44] G. Büyüközkan and G. Çifçi, "A novel hybrid MCDM approach based on fuzzy DEMATEL, fuzzy ANP and fuzzy TOPSIS to evaluate green suppliers," Expert Systems with Applications, vol. 39, no. 3, pp. 3000-3011, 2012.

[45] M. Behzadian, R. B. Kazemzadeh, A. Albadvi, and M. Aghdasi, "PROMETHEE: a comprehensive literature review on methodologies and applications," European Journal of $\mathrm{Op}$ erational Research, vol. 200, no. 1, pp. 198-215, 2010.

[46] A. Albadvi, S. K. Chaharsooghi, and A. Esfahanipour, "Decision making in stock trading: an application of PROMETHEE," European Journal of Operational Research, vol. 177, no. 2, pp. 673-683, 2007. 
[47] K. S. Dong Qiao, J. Wang, and T. Wang, "Multi-criteria PROMETHEE method based on possibility degree with $Z$ numbers under uncertain linguistic environment," Journal of Ambient Intelligence and Humanized Computing, 2019.

[48] G. Kabir and R. S. Sumi, "Power substation location selection using fuzzy analytic hierarchy process and PROMETHEE: a case study from Bangladesh," Energy, vol. 72, no. 2, pp. 717-730, 2014.

[49] D. Raman, S. V. Nagalingam, and G. C. I. Lin, "Towards measuring the effectiveness of a facilities layout," Robotics and Computer-Integrated Manufacturing, vol. 25, no. 1, pp. 191203, 2009.

[50] N. C. Tsourveloudis and Y. A. Phillis, "Manufacturing flexibility measurement: a fuzzy logic framework," IEEE Transactions on Robotics and Automation, vol. 14, no. 4, pp. 513-524, 1998.

[51] P. Sharma and S. Singhal, "Implementation of fuzzy TOPSIS methodology in selection of procedural approach for facility layout planning," International Journal of Advanced Manufacturing Technology, vol. 88, no. 5, pp. 1-9, 2016.

[52] H. Liao and X. Wu, "A consensus-based probabilistic linguistic gained and lost dominance score method," European Journal of Operational Research, vol. 272, no. 3, pp. 1017-1127, 2019.

[53] X. Wu, Z. Fu, H. Liao, and F. Herrera, "Underground Mining method selection with the hesitant fuzzy linguistic gained and lost dominance score method," IEEE Access, vol. 6, pp. 66442-66458, 2018.

[54] H. M. B. Dehghan-Manshadi, A. Abedian, and R. Mahmudi, "A novel method for materials selection in mechanical design: combination of non-linear normalization and a modified digital logic method," Materials \& Design, vol. 2007, no. 28, pp. 8-15, 2007.

[55] R.-x. Nie, Z.-p. Tian, J.-q. Wang, H.-y. Zhang, and T.-l. Wang, "Water security sustainability evaluation: applying a multistage decision support framework in industrial region," Journal of Cleaner Production, vol. 196, pp. 1681-1704, 2018. 